\title{
LEVENBERG-MARQUARDT APPLICATION TO TWO-PHASE NONLINEAR PARAMETER ESTIMATION FOR FINNED-TUBE COIL EVAPORATORS
}

\author{
S. S. BUENO, J. P. DIAS, A. L. SEIXLACK, AND J. B. APARECIDO \\ Received 30 August 2004; Revised 19 June 2005; Accepted 7 July 2005
}

A procedure for calculation of refrigerant mass flow rate is implemented in the distributed numerical model to simulate the flow in finned-tube coil dry-expansion evaporators, usually found in refrigeration and air-conditioning systems. Two-phase refrigerant flow inside the tubes is assumed to be one-dimensional, unsteady, and homogeneous. In the model the effects of refrigerant pressure drop and the moisture condensation from the air flowing over the external surface of the tubes are considered. The results obtained are the distributions of refrigerant velocity, temperature and void fraction, tube-wall temperature, air temperature, and absolute humidity. The finite volume method is used to discretize the governing equations. Additionally, given the operation conditions and the geometric parameters, the model allows the calculation of the refrigerant mass flow rate. The value of mass flow rate is computed using the process of parameter estimation with the minimization method of Levenberg-Marquardt minimization. In order to validate the developed model, the obtained results using HFC-134a as a refrigerant are compared with available data from the literature.

Copyright (c) 2006 S. S. Bueno et al. This is an open access article distributed under the Creative Commons Attribution License, which permits unrestricted use, distribution, and reproduction in any medium, provided the original work is properly cited.

\section{Introduction}

The preoccupation with ecological issues is gaining, nowadays, very much attention, mainly in concern with atmospheric ozone layer, greenhouse effect, and requirement of new less pollutant sources of energy. In the refrigeration field, such concern has motivated several researches and big investment aiming to improve thermodynamic efficiency of its main components: evaporators, condensers, compressors, and expansion devices. The fundamental subject of these researches is to analyze the behavior of devices when operating with refrigerant fluids less aggressive to the atmospheric ozone layer.

Several studies about evaporators has been done, aiming (i) to obtain operating parameters of this kind of heat exchangers, such as heat transfer coefficient, pressure drop along the flow, and cooling capacity; (ii) to develop new evaporators well adapted to use 


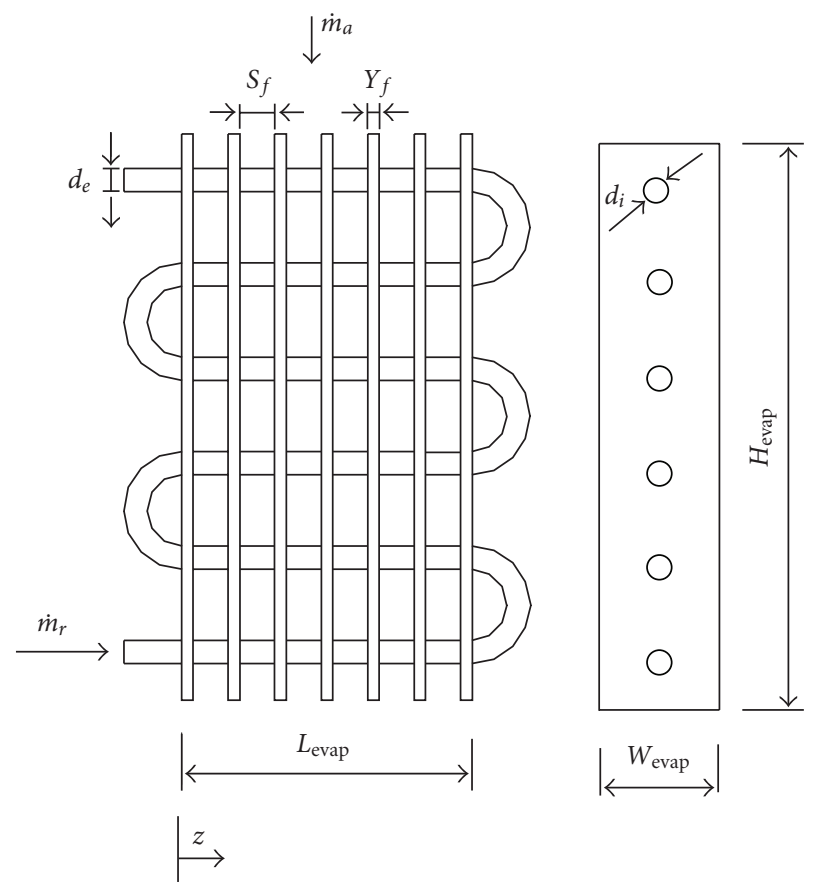

Figure 1.1. Schematic and geometrical parameters of a finned-tube coil evaporator.

alternative refrigerant fluids to CFCs and HCFCs; (iii) to develop and characterize the performance of new kinds and geometries of fins, and turbulence enhancers to intensify the heat transfer coefficient.

The refrigerant fluid flow inside evaporator tubes is complex and generally, due to phase change, it is possible to find two regions: a two-phase flow (liquid-vapor) and a superheated vapor flow. Further, during the refrigeration system operation, long unsteady periods can happen as a consequence, for example, of starting or stopping the system, starting or stopping the compressor, and variation of operating conditions of the system. During such periods, the two-phase flow or superheated vapor flow regions can appear or disappear, making the flow modeling more difficult.

Usually, the heat transfer process between the refrigerant and the air in a finned-tube coil evaporator happens in cross-flows, as shown in Figure 1.1. To improve the heat transfer efficiency or to seek ideal operating conditions, several tube arrangements are used and various methods to choose the best layout are utilized.

Several studies, dealing with different aspects about the performance of finned-tube coil evaporators can be found in the literature: Jia et al. [7], Liang et al. [9, 10], and Barbieri [2]. The most of research refers to heat exchangers used in commercial refrigeration and in air-conditioning systems. Due to various phenomena involved in evaporators operation, different aspects have been analyzed, such as air distribution effect on the evaporator performance; the influence of shape and layout of evaporators tubes; fin 
type; evaporator dynamical behavior when submitted to different operating conditions; and others.

Barbieri [2] developed a distributed numerical model to simulate the unsteady behavior of finned-tube coil dry-expansion evaporators. The results obtained by Barbieri [2] indicated that the model satisfactorily predicted the unsteady behavior of an evaporator subjected to a step change in the inlet refrigerant mass flow rate. In this work, the model proposed by Barbieri [2] is extended with a numerical procedure that allows the computation of refrigerant mass flow rate, once the evaporator geometrical parameters and operating conditions are known, aiming at the analysis of the evaporator performance. The minimization method of Levenberg and Marquardt is used to do the estimation of mass flow rate and the results obtained are compared to those ones of Liang et al. [9].

\section{Mathematical model}

The refrigerant fluid flow inside the evaporator tube is divided into two regions: a twophase flow (liquid-vapor) and another one with superheated vapor flow. Pressure drop inside the tubes and the moisture condensation on air side are considered.

In order to simplify the problem, the following assumptions are done: (a) the evaporator has just one circuit (see Figure 1.1), since the refrigerant mass flow rate is taken to be uniform along each circuit and the heat conduction among those circuits is neglected; (b) the two-phase flow inside the tubes is taken to be one-dimensional and homogeneous; (c) the change in refrigerant potential energy is also neglected; (d) the heat transfer coefficient is uniform on the air side (may be different on dry and wet coil regions); (e) the heat conduction in the tube wall is neglected; ( $\mathrm{f}$ ) the air flow is incompressible; $(\mathrm{g})$ there is no ice formation; (h) the refrigerant is oil-free.

The governing equations for the flow inside the tube are divided according to the kind of flow: single-phase or two-phase. The equations presented bellow is related to the twophase flow region. Considering the void fraction $\alpha=1$, in such equations, the governing equations are obtained to the superheated vapor region.

Based on the above assumptions, considering the evaporator geometrical parameters, shown in Figure 1.1, and applying the principles of mass conservation, momentum, and energy conservation for the refrigerant, the following governing equations are obtained, respectively, to the refrigerant flow:

$$
\begin{gathered}
\frac{\partial \tilde{\rho}}{\partial t}+\frac{\partial(\tilde{\rho} u)}{\partial z}=0, \\
\frac{\partial(\tilde{\rho} u)}{\partial t}+\frac{\partial\left(\tilde{\rho} u^{2}\right)}{\partial z}=-\frac{\partial p}{\partial z}-F_{x}, \\
\frac{\partial\left(\tilde{\rho} h_{r}\right)}{\partial t}+\frac{\partial\left(\tilde{\rho} u h_{r}\right)}{\partial z}=\frac{\partial p}{\partial t}+\frac{A_{i}^{\prime}}{A_{\mathrm{tub}}} d q_{w r}^{\prime \prime},
\end{gathered}
$$

where $\tilde{\rho}=\left[\alpha \rho_{v}+(1-\alpha) \rho_{l}\right]$ is the density $\left(\mathrm{kg} / \mathrm{m}^{3}\right), \alpha=\left\{1+\left[\rho_{v}(1-x) / \rho_{l} x\right]\right\}^{-1}$ is the void fraction, $x$ is the vapor quality, $u=G_{r} / \tilde{\rho}$ is the flow average velocity $(\mathrm{m} / \mathrm{s}), G_{r}$ is the refrigerant mass flux $\left(\mathrm{kg} / \mathrm{m}^{2} \mathrm{~s}\right), t$ is the time $(\mathrm{s}), z$ is the coordinate along the evaporator tube ( $\mathrm{m})$ (see Figure 1.1), and $p$ is the flow pressure inside the tube $(\mathrm{Pa})$, calculated by using 
the state equation $p=p\left(\tilde{\rho}, h_{r}\right)$ presented by Barbieri [2]. The subscripts $l$ and $v$ indicate, respectively, the liquid and vapor phases. In (2.2), $F_{x}=\left(d p_{F} / d z\right)$ is the friction pressure loss $\left(\mathrm{N} / \mathrm{m}^{3}\right)$.

In (2.3), $h_{r}=\left[x h_{v}+(1-x) h_{l}\right]$ is the refrigerant enthalpy $(\mathrm{J} / \mathrm{kg}), h_{l}$ and $h_{v}$ are, respectively, the liquid and vapor enthalpies $(\mathrm{J} / \mathrm{kg}), A_{i}$ is the tube-inner-wall area by unity length (m), $A_{\text {tub }}$ is the inside cross-section area of tube $\left(\mathrm{m}^{2}\right), d q_{w r}^{\prime \prime}=\left[H_{r}\left(T_{w}-T_{r}\right)\right]$ is the heat flux from the tube wall to the refrigerant $\left(\mathrm{W} / \mathrm{m}^{2}\right), H_{r}$ is the heat transfer coefficient inside the tube $\left(\mathrm{W} / \mathrm{m}^{2} \mathrm{~K}\right), T_{w}$ is the tube-wall temperature $\left({ }^{\circ} \mathrm{C}\right)$, and $T_{r}$ is the refrigerant temperature $\left({ }^{\circ} \mathrm{C}\right)$.

The finned-tube coils are largely used in applications for atmospheric air cooling, with the occurrence of the moisture condensation on the air side being common. Because of dehumidification, a liquid water film that eventually could freeze covers the coil surface on the air side. Thus, the cooling and dehumidifying process involves both sensible and latent heat transfers.

To obtain the governing equations for the air flow, besides the previous assumptions, the thermal inertia of the air is neglected. Applying the principles of mass conservation (humidity) and energy conservation for the air, the following equations are obtained, respectively:

$$
\begin{gathered}
\dot{m}_{a} \frac{d \omega_{a}}{d z} d z=H_{m} A_{t}^{\prime} d z\left(\omega_{a}-\omega_{a, \text { sat }}\right) \\
\dot{m}_{a} \frac{d h_{a}}{d z} d z=H_{a} A_{t}^{\prime} d z\left(T_{a}-T_{w}\right)+H_{m} A_{t}^{\prime} d z \lambda_{\text {water }}\left(\omega_{a}-\omega_{a, \text { sat }}\right)+H_{m} A_{t}^{\prime} d z\left(\omega_{a}-\omega_{a, \text { sat }}\right) h_{l, \text { water }},
\end{gathered}
$$

where $\dot{m}_{a}=\left[\rho_{a} u_{a}\left(W_{\text {evap }} L_{\text {evap }}\right)\right]$ is the air mass flow rate $(\mathrm{kg} / \mathrm{s}), \rho_{a}$ is the air density $\left(\mathrm{kg} / \mathrm{m}^{3}\right)$, $u_{a}$ is the air velocity $(\mathrm{m} / \mathrm{s}), L_{\text {evap }}$ is the evaporator straight length $(\mathrm{m}), W_{\text {evap }}$ is the evaporator width $(\mathrm{m}), A_{t}^{\prime}=\left(A_{r}^{\prime}+A_{f}^{\prime} \eta_{f}\right)$ is the heat transfer total area by unity length $(\mathrm{m}), A_{r}^{\prime}$ is the outer area not covered by fins by unity length $(\mathrm{m}), A_{f}^{\prime}$ is the fins surface area by unity length (m), $\eta_{f}$ is the fin efficiency presented by McQuiston and Parker [13], $H_{a}$ is the air heat transfer coefficient $\left(\mathrm{W} / \mathrm{m}^{2} \mathrm{~K}\right), T_{a}$ is the air temperature $\left({ }^{\circ} \mathrm{C}\right), \omega_{a}$ is the air absolute humidity, $\omega_{a \text {,sat }}$ is the saturated air humidity at temperature $T_{w}, \lambda_{\text {water }}$ is the latent heat of water condensation at temperature $T_{w}(\mathrm{~J} / \mathrm{kg}), h_{l \text {,water }}$ is the liquid water enthalpy at temperature $T_{w}(\mathrm{~J} / \mathrm{kg})$, and $H_{m}$ is the mass transfer coefficient $\left(\mathrm{kg} / \mathrm{m}^{2} \mathrm{~s}\right)$, calculated by the Lewis correlation $\left[H_{m}=H_{a} / \operatorname{Lec}_{p, a}\right]$, where Le is the Lewis number, Le $=\left[k_{a} /\left(\rho_{a} c_{p, a} D_{a b}\right)\right]$, $D_{a b}$ is the water-air mass diffusivity $\left(\mathrm{m}^{2} / \mathrm{s}\right), k_{a}$ is the air thermal conductivity $(\mathrm{W} / \mathrm{mK})$, and $c_{p, a}$ is the specific heat at constant pressure for the air $(\mathrm{J} / \mathrm{kgK})$.

Applying the principle of energy conservation at tube wall,

$$
M_{w f}^{\prime} \mathcal{C}_{w f} \frac{d T_{w}}{d t}=H_{a} A_{t}^{\prime} d z\left(T_{a}-T_{w}\right)+H_{m} A_{t}^{\prime} d z \lambda_{\text {water }}\left(\omega_{a}-\omega_{a, \text { sat }}\right)-H_{r} A_{i}^{\prime} d z\left(T_{w}-T_{r}\right)
$$

is obtained, where $M_{w f}^{\prime}$ are the fins and tube-wall mass by unity length and $c_{p, w f}$ is the average specific heat at constant pressure, considering the tube and fins materials (see Barbieri [2]). 
The system constituted by (2.1)-(2.5) must be solved to compute variables $\tilde{\rho}, u, h_{r}$, $T_{a}, T_{w}$, and $\omega_{a}$. To perform such task, constitutive equations are required in order to compute the refrigerant and air thermophysical properties, the friction coefficient, the heat transfer coefficients to the refrigerant and to the air, and the mass transfer coefficient to the air.

Air and water thermophysical properties are obtained, respectively, from data presented by ASHRAE [1] and Incropera and Dewitt [6]. The properties of the refrigerant fluid and tube-wall material are computed, respectively, by using the data given by McLinden et al. [11] and Incropera and Dewitt [6]. Moreover, the model uses the following correlations to compute other parameters:

(1) friction factor in the superheated vapor region, see Churchill [4];

(2) pressure drop due to shear in the two-phase flow region, see Paliwoda [14];

(3) heat transfer coefficient in the single-phase flow region, see Dittus and Boelter [5];

(4) heat transfer coefficient in the two-phase flow region, see Jung and Radermacher [8] and Chen [3];

(5) heat transfer coefficient on the air side, see McQuiston [12] and Turaga et al. [15].

\section{Initial conditions and solution methodology}

For a given coil, the model could be used to (a) determine evaporator performance parameters, such as refrigeration load, outlet refrigerant, and air temperatures, among others, since the evaporator operating conditions and dimensions are known. In this case a direct problem is solved, departing from a set of inlet conditions for the refrigerant and also for the air; (b) determine the refrigerant mass flow rate along evaporator tubes, once its dimensions and other operating conditions are known. In this case, an inverse problem must be solved, since the conservation equations are mass-flow-rate-dependent. The solution procedure chosen in each case is shown as follows. Figure 3.1 gives the flux diagram of the numerical algorithm used to solve both direct and inverse problems.

3.1. Direct problem. In this case, the solution for the system (2.1)-(2.5) is obtained from known refrigerant conditions $\dot{m}_{r}, x$, and $T_{r}$, at the tube inlet and from known air conditions $T_{a}, \omega_{a}$, and $\dot{m}_{a}$ at evaporator inlet.

The numerical solution for this system of equations is obtained by using the finite volume method with staggered grid for a relative placement of variables in the computational mesh. Since the problem is strongly convective, an upwind scheme is used to discretize the governing equations.

To improve the efficiency of the solution process, an iterative method is utilized in two levels. First, refrigerant and tube-wall variables computed (see Figure 3.1). Second, variables for the air are calculated. The Newton-Raphson method cell by cell is used to solve the system of equations.

In the air side, the correction of temperature and humidity values is done for the whole mesh and not cell by cell. Convergence is achieved when the summation of all corrections of the air conditions $T_{a}$ and $\omega_{a}$ will be less than $10^{-4}$. It is considered that the steady-state 


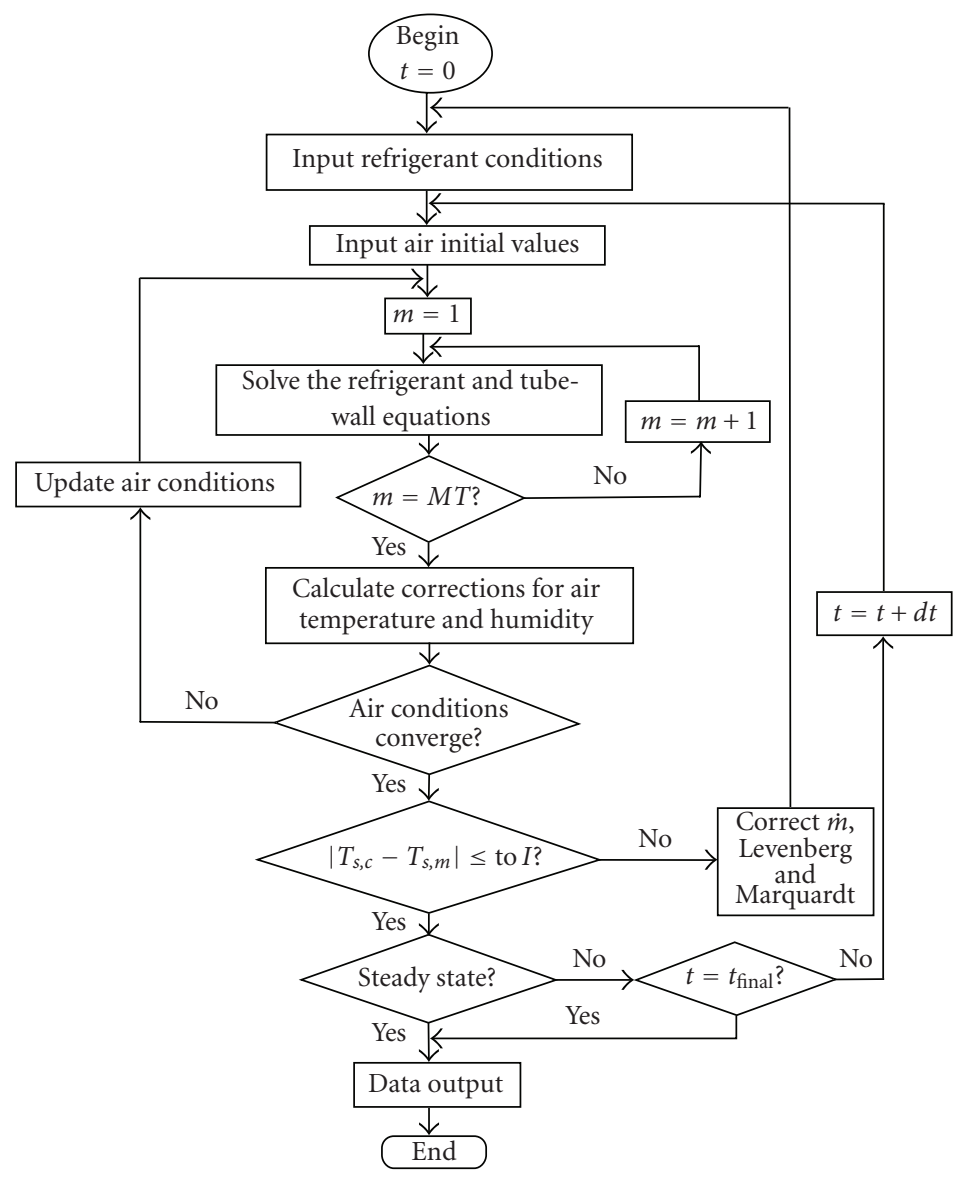

Figure 3.1. Flowchart of the numerical algorithm.

regime is reached when a change of $\tilde{\rho}, u, h_{r}$, and $T_{w}$, from a time step to another is less than $10^{-3}$.

Once the steady-state regime is achieved, the refrigerant mass flow rate can be increased or decreased to simulate the evaporator unsteady behavior. As the evaporator is in steady-state regime, this perturbation will promote an unsteady-state period followed by a steady state. Such change in refrigerant mass flow rate simulates varying operation system conditions.

3.2. Inverse problem. The inverse problem corresponds to that one which is desired to calculate the refrigerant mass rate along the evaporator once its geometry and working conditions are known.

Since the problem is nonlinear due to the fact that conservation equations are mass dependent, an additional calculation procedure is necessary, beyond that presented in 
Section 3.1. Therefore, the initial value of $\dot{m}_{r}$ is guessed and the refrigerant temperature at the coil exit $T_{s, c}$ is calculated and compared to the respective measured (or computed using another model) value $T_{s, m}$. After that, the value of $\dot{m}_{r}$ is corrected by using the nonlinear parameter estimation method of Levenberg and Marquardt. The process is repeated until some convergence criteria are matched.

Consider the problem of minimizing a function $F$ of one independent variable, when $F$ can be expressed as a sum of functions squared. In the least square method, $F$ must have the following quadratic aspect: $F(s)=\sum_{i=2}^{m} f_{i}^{2}$, where $F(s)$ is defined as $F(s)=\left[f^{T}(s) f(s)\right]$ and $f(s)=[f(s)]^{T}$.

In this work, the vector $\mathbf{s}$ and the function $F(\mathbf{s})$ are, respectively, defined by $s=\left[\dot{m}^{*}\right]^{T}$ and $F(s)=\left[T_{s, c}\left(\dot{m}^{*}\right)-T_{s, m}\right]^{2}$. Then $f(s)=\left[T_{s, c}\left(\dot{m}^{*}\right)-T_{s, m}\right]$, in which $\dot{m}^{*}$ is the mass flow rate and $T_{s, c}$ is the temperature at tube outlet, both computed iteratively.

An increment $\mathbf{t}_{k}$ is the solution of the following linear system:

$$
\left(J_{k}^{T} J_{k}+\varphi_{k} I\right) t_{k}=-J_{k}^{T} f_{k}, \quad \varphi_{k} \geq 0
$$

where $J_{k}=\left[f\left(\dot{m}^{*}+\delta\right)-f\left(\dot{m}^{*}\right) / \delta\right]$ is the Jacobian matrix, $\varphi_{k}$ is the Levenberg-Marquardt parameter, initially equal to 0.01 , and $\mathbf{I}$ is the identity matrix. All variables are computed at the $k$ th iteration.

Once the increment $\mathbf{t}_{k}$ is computed, the vector $\mathbf{s}_{k}$ is updated to give a new value $\mathbf{s}_{k+1}$ to the trial solution as $s_{k+1}=\left(s_{k}+t_{k}\right), k=0,1,2 \ldots$. This method uses the $F$ (s) gradient vector norm in each step as stopping criterion, comparing it with a previously established tolerance $\xi$. Levenberg-Marquardt method uses a parameter $\varphi_{k}\left(\varphi_{0}=0.01\right)$, related to another parameter $\gamma=5$, that is updated in a given step as follows:

$$
\begin{gathered}
F\left(s_{k+1}\right) \geq F\left(s_{k}\right) \Longrightarrow \varphi_{k+1}=\varphi_{k} \gamma, \\
F\left(s_{k+1}\right)<F\left(s_{k}\right) \Longrightarrow \varphi_{k+1}=\frac{\varphi_{k}}{\gamma} .
\end{gathered}
$$

When $\varphi_{k} \rightarrow 0, \mathbf{t}_{k}$ is the same as that one provided by the Gauss-Newton method and when $\varphi_{k} \rightarrow \infty$, the term $\varphi_{k} \mathbf{I}$ dominates the term $\mathbf{J}_{k}{ }^{T} \mathbf{J}_{k}$, and therefore $\mathbf{t}_{k}=-\mathbf{J}_{k}{ }^{T} \mathbf{f}_{k} / \varphi_{k}$ representing an infinitesimal increment of that one provided by the steepest descent method. This means that the Levenberg-Marquardt method is able to shift continuously from the steepest descent method to the Gauss-Newton method.

The computational procedure, utilizing the Levenberg-Marquardt method is given shortly by the following:

(1) enter starting data as initial guess $\mathbf{s}_{0}$, gradient tolerance $\xi$, and parameters $\varphi_{o}=$ 0.01 , and $\gamma=5$;

(2) solve the ordinary differential equation system (2.1)-(2.5), for $s=\left[\dot{m}^{*}+\delta\right]^{T}$;

(3) compute Jacobian, $\mathbf{J}_{k}$;

(4) compute $\mathbf{t}_{k}$, by solving the linear system, using (3.1);

(5) compute $\mathbf{s}_{k+1}$, calculating $\mathbf{s}_{k+1}=\mathbf{s}_{k}+\mathbf{t}_{k}$;

(6) compute $F_{k+1}\left(\mathbf{s}_{k+1}\right)$;

(7) if $F_{k+1}>F_{k}$, then $\varphi_{k+1}=\varphi_{k} \gamma$; 
Levenberg-Marquardt application to parameter estimation

Table 4.1. Evaporator geometrical parameters simulated by Liang et al. [9].

\begin{tabular}{lc}
\hline Geometrical parameters & Values \\
\hline Straight tube length $(\mathrm{m})$ & 1.0 \\
Transversal tube spacing $(\mathrm{m})$ & 0.025 \\
Longitudinal tube spacing $(\mathrm{m})$ & 0.0216 \\
Tube outer diameter $(\mathrm{mm})$ & 9.53 \\
Tube inner diameter $(\mathrm{mm})$ & 8.83 \\
Fins thickness $(\mathrm{mm})$ & 0.12 \\
Fins spacing $(\mathrm{mm})$ & 2.41 \\
Quantity of fins & 394 \\
\hline
\end{tabular}

(8) if $F_{k+1}<F_{k}$, then $\varphi_{k+1}=\varphi_{k} / \gamma$;

(9) compute the gradient norm $\left\|\nabla F\left(\mathbf{s}_{k+1}\right)\right\|=\left\|\mathbf{g}_{k+1}\right\|$;

(10) if $\left\|\mathbf{g}_{k+1}\right\| \geq \xi$, then return to (2);

(11) if $\left\|\mathbf{g}_{k+1}\right\|<\xi$, stop.

\section{Results and discussion}

In this work, we presented some comparison among results for the steady-state regime computed using the present model and results obtained by Liang et al. [9], for the direct problem as well as for the inverse problem. Geometrical parameters for the evaporator analyzed by Liang et al. [9] are presented in Table 4.1 .

In Figures 4.1 and 4.2, for relative humidity of air at evaporator inlet, relative humidity of $60 \%$ and $90 \%$, some comparison of the air temperature profile, the refrigerant temperature, and the tube-wall temperature calculated using the present model with the results computed by Liang et al. [9] are presented, respectively. For these cases, the direct problem is solved considering known refrigerant mass flow rate of $0.0055 \mathrm{~kg} / \mathrm{s}$ and $0.0086 \mathrm{~kg} / \mathrm{s}$, respectively, for relative humidity of air at evaporator inlet of $60 \%$ and $90 \%$. The other operating conditions used by Liang et al. [9], for such cases, are presented in Table 4.2. The enthalpy at evaporator inlet is determined through operating conditions at condenser exit (condensation temperature $=45^{\circ} \mathrm{C}$, subcooling degree $=5^{\circ} \mathrm{C}$ ).

In Figures 4.1 and 4.2, a good agreement among results presented by Liang et al. [9] and the results calculated using the present model, mainly for refrigerant tube-wall temperature profiles are verified. The refrigerant vapor quality in the coil exit is 0.81 differing from Liang et al. [9] results. In spite of this, the temperature profiles for the air, the refrigerant, and the tube wall are well approximated, with a major difference just in the region of superheat steam.

In Figure 4.3, it is shown that the refrigerant mass flow rate changes as a function of the air relative humidity at evaporator inlet. In this case, the inverse problem is solved; thus, the mass flow rate is computed, with the evaporator geometrical parameters and the operating conditions known. The geometric parameters for the tube and fins are the same presented in Table 4.1, with the operating conditions corresponding to the case 01 presented in Table 4.2. Computed values for the mass flow rate are compared to those ones obtained by Liang et al. [9] for a relative humidity range from $20 \%$ up to $90 \%$. 
S. S. Bueno et al. 9

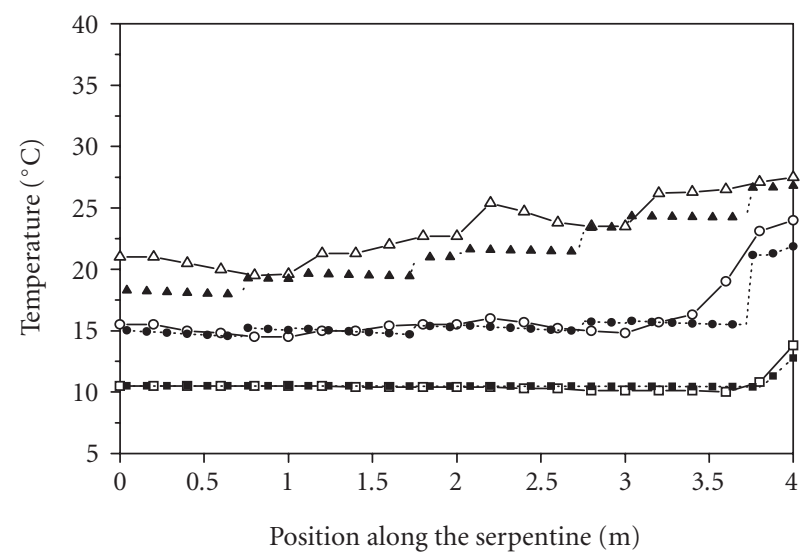

Refrigerant temperature: Tube-wall temperature: Air temperature:

........ Present model $\quad$ …... Present model $\quad \cdots . .$. Present model

Figure 4.1. Comparison among temperature profiles for air $\left(\mathrm{Va}=2 \mathrm{~m} / \mathrm{s} ; \mathrm{Ta}_{\mathrm{in}}=28{ }^{\circ} \mathrm{C}\right)$, tube wall, and refrigerant for relative humidity $=60 \%$.

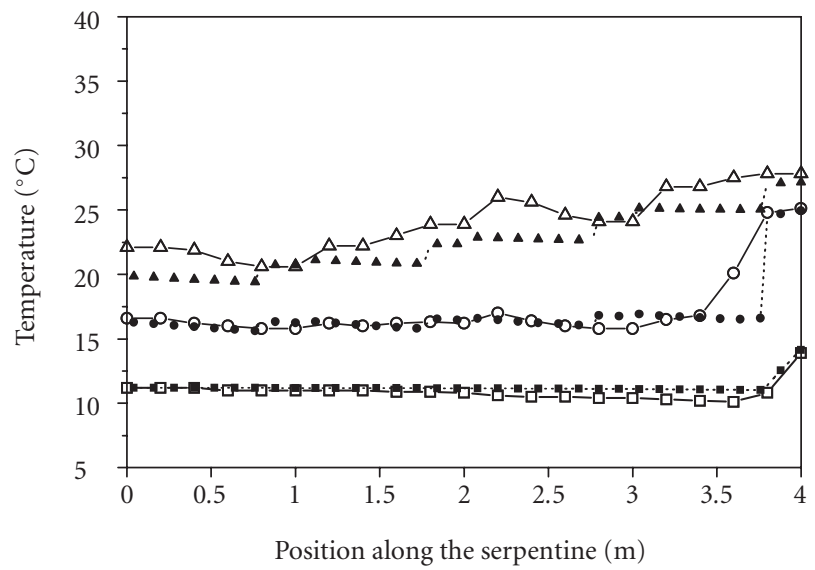

Refrigerant temperature: Tube-wall temperature: Air temperature:

........ Present model $\quad$........ Present model $\quad$....... Present model

—— Liang et al. [9] ——Liang et al. [9] —- Liang et al. [9]

Figure 4.2. Comparison among temperature profiles for air $\left(\mathrm{Va}=2 \mathrm{~m} / \mathrm{s} ; \mathrm{Ta}_{\text {in }}=28^{\circ} \mathrm{C}\right)$, tube wall, and refrigerant for relative humidity $=90 \%$.

Notice that in Figure 4.3 the major deviations among results occur for relative humidity below $50 \%$. Such deviation is due to the fact that for low humidity, the present model 
Table 4.2. Operating conditions (see Liang et al. [9]).

\begin{tabular}{lcc}
\hline Operation conditions at inlet & Case 01 & Case 02 \\
\hline Refrigerant temperature $\left({ }^{\circ} \mathrm{C}\right)$ & 10.5 & 11.0 \\
Refrig. mass flow rate $10^{3}(\mathrm{~kg} / \mathrm{s})$ & 5.5 & 8.6 \\
Vapor quality & 0.22 & 0.22 \\
Air temperature $\left({ }^{\circ} \mathrm{C}\right)$ & 28.0 & 28.0 \\
Relative humidity $(\%)$ & 60 & 90 \\
Air velocity $(\mathrm{m} / \mathrm{s})$ & 2.0 & 2.0 \\
\hline
\end{tabular}

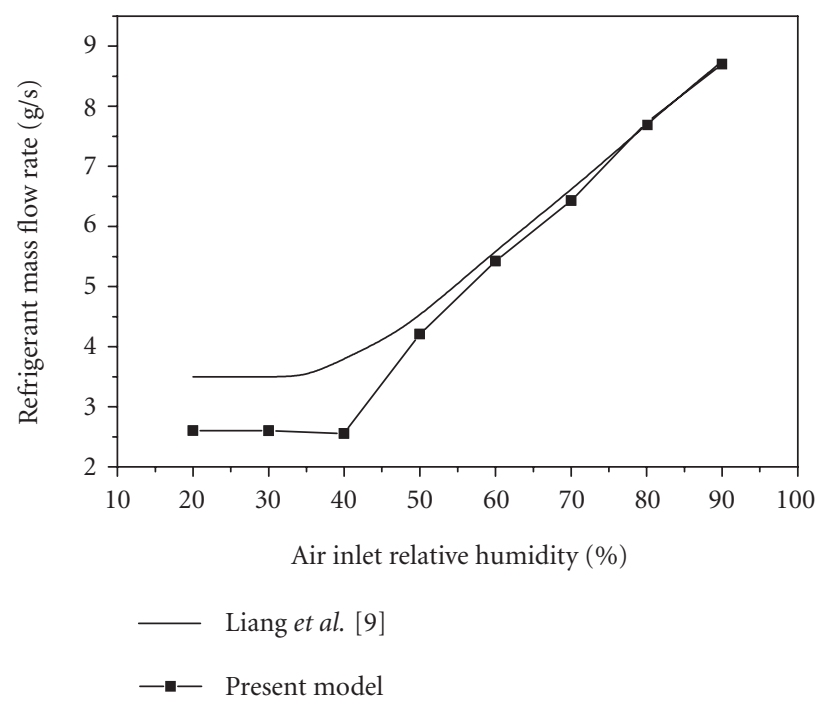

Figure 4.3. Refrigerant mass flow rate as function of air relative humidity at evaporator inlet $\left(\mathrm{Ta}_{\text {in }}=\right.$ $28^{\circ} \mathrm{C} ; \mathrm{Va}=2 \mathrm{~m} / \mathrm{s}$ ).

does not predict the refrigerant complete vaporization (see Barbieri [2]). For relative humidity above $50 \%$, there is a good agreement among those results, and considering whole air relative humidity range, from 20 up to $90 \%$, the average absolute deviation from Liang et al. [9] results is $12.1 \%$. Yet, a significant increase in refrigerant mass flow rate for relative humidity above $40 \%$ is also observable. That behavior, as shown by Liang et al. [9] and Barbieri [2], is due to the increase of the cooling load needed, which approximately is double of its value for humidities in the range from 50 up to $90 \%$. The increase on cooling load is mainly due to the quick increase in the portion of latent heat as a consequence of the increase of air relative humidity.

In Figure 4.4, the refrigerant mass flow rate change as a function of evaporation temperature and the air temperature at evaporator inlet are presented. Once more, the tube 


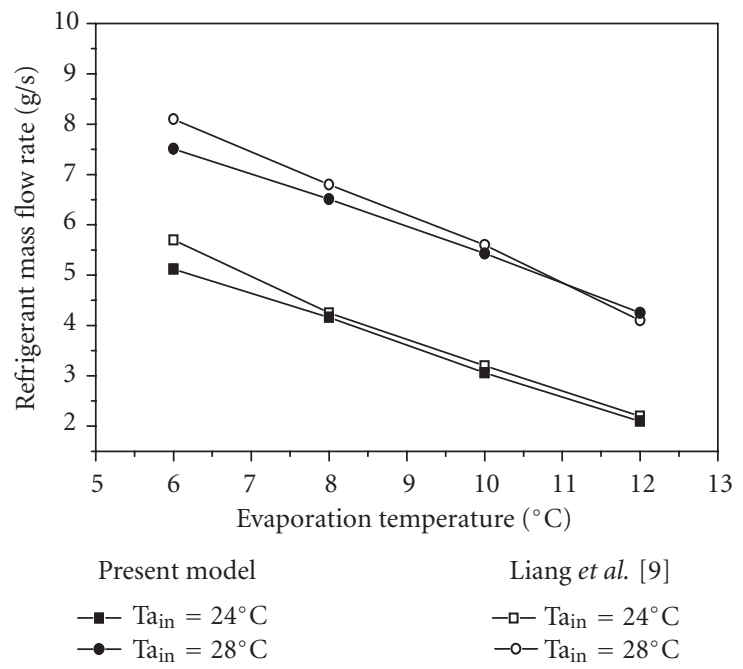

Figure 4.4. Refrigerant mass flow rate as function of evaporation temperature and air temperature at evaporator inlet.

and fins geometrical parameters are those available on Table 4.1. The operating conditions are refrigerant superheating degree of $5^{\circ} \mathrm{C}$, air velocity at inlet of $2 \mathrm{~m} / \mathrm{s}$, air relative humidity of $60 \%$, and evaporation temperature of $24^{\circ} \mathrm{C}$ and $28^{\circ} \mathrm{C}$. For such cases, the average absolute deviation between the mass flow rate values calculated by using the present model and those ones obtained by Liang et al. [9] is of 5\%.

Keeping the air inlet temperature constant, one can observe on Figure 4.4 that the refrigerant mass flow rate, necessary to keep the same refrigerant superheating degree, decreases with the increase in the evaporation temperature. In the same way, for the same evaporation temperature, the refrigerant mass flow rate decreases with the decreasing in air inlet temperature.

\section{Conclusion}

In this work, a procedure to compute the mass flow rate for refrigerant fluids along finned-tube coil dry-expansion evaporators is presented. To achieve that goal, a process of parameter estimation by using the minimization method of Levenberg and Marquardt is used.

Such method presented high efficacy to determine the mass flow rate, without any numerical instability. Due to its robustness, the Levenberg-Marquardt method does not present divergence or oscillation problems during iteration process. Hence, this method overcomes the Newton-Raphson method that is conditionally convergent, or is frequently unstable depending strongly on the initial guess.

Such instability and nonconvergence problems were found in some tested cases, since the Newton-Raphson method is still used in part of the computational code to solve the nonlinear governing equations, both for the refrigerant as well as for the air flows. Some 
of such cases presented convergence difficulties and other ones presented oscillatory behavior around some points, resulting in the nonconvergence of the iteration process. This fact implies the necessity to implement in the computational code more efficient methods to solve the nonlinear system of governing equations.

\section{Acknowledgment}

Authors acknowledge FAPESP-Fundação de Amparo à Pesquisa do Estado de São Paulo and CNPQ/PIBIC/UNESP for their financial support that is allowing the development of this project.

\section{References}

[1] ASHRAE, Fundamental Handbook, chapter 6, American Society of Heating, Refrigerating and Air-Conditioning Engineers, Georgia, 1993.

[2] P. E. L. Barbieri, Dynamic analysis of evaporators with finned tube coils, M.Sc. Thesis, Department of Mechanical Engineering, São Paulo State University - UNESP, São Paulo, 2001.

[3] J. C. Chen, A correlation for boiling heat transfer to saturated fluids in convective flow, Industrial and Engineering Chemistry Process Design and Development 5 (1966), no. 3, 322-329.

[4] S. W. Churchill, Friction factor equation spans all fluid flow regimes, Chemical Engineering 84 (1977), no. 24, 91-92.

[5] F. W. Dittus and L. M. K. Boelter, Heat Transfer in Automobile Radiators of the Tubular Type, University of California Publications in Engineering, vol. 2, University of California Press, Berkeley, 1930.

[6] F. P. Incropera and D. P. Dewitt, Fundamentals of Heat and Mass Transfer, John Wiley \& Sons, New York, 2003.

[7] X. Jia, C. P. Tso, P. Jolly, and Y. W. Wong, Distributed steady and dynamic modelling of dryexpansion evaporators, International Journal of Refrigeration 22 (1999), no. 2, 126-136.

[8] S. D. Jung and R. Radermacher, Prediction of heat transfer coefficients of various refrigerants during evaporation, ASHRAE Transactions 97 (1991), part 2, 48-53.

[9] S. Y. Liang, M. Liu, T. N. Wong, and G. K. Nathan, Analytical study of evaporator coil in humid environment, Applied Thermal Engineering 19 (1999), no. 11, 1129-1145.

[10] S. Y. Liang, T. N. Wong, and G. K. Nathan, Numerical and experimental studies of refrigerant circuitry of evaporator coils, International Journal of Refrigeration 24 (2001), no. 8, 823-833.

[11] M. O. McLinden, S. A. Klein, E. W. Lemmon, and A. P. Peskin, Users' Guide: Thermodynamic and Transport Properties of Refrigerants and Refrigerant Mixtures-REFPROP, Software Version 6.0, National Institute of Standards and Technology, Colorado, 1998.

[12] F. C. McQuiston, Finned tube heat exchangers: state of the art for the air side, ASHRAE Transactions 87 (1981), 1077-1085.

[13] F. C. McQuiston and J. D. Parker, Heating, Ventilating and Air Conditioning: Analysis and Design, 4th ed., John Wiley \& Sons, New York, 1994.

[14] A. Paliwoda, Generalized method of pressure drop and tube length calculation with boiling and condensing refrigerants within the entire zone of saturation, International Journal of Refrigeration 12 (1989), no. 6, 314-322. 
[15] M. Turaga, S. Lin, and P. P. Fazio, Correlation for heat transfer and pressure drop factors for direct expansion air cooling and dehumidifying coils, ASHRAE Transactions, 94 (1988), part 2, 616-629.

S. S. Bueno: Products Research \& Development, Tecumseh do Brasil Ltda.,

P. O. Box 54, CEP 13565-900, São Carlos, SP, Brazil

E-mail address: sbueno@tecumseh.com.br

J. P. Dias: Department of Mechanical Engineering, São Paulo State University, (UNESP),

P. O. Box 31, CEP 15385-000, Ilha Solteira, SP, Brazil

E-mail address: jpdias@dem.feis.unesp.br

A. L. Seixlack: Department of Mechanical Engineering, São Paulo State University, (UNESP), P. O. Box 31, CEP 15385-000, Ilha Solteira, SP, Brazil

E-mail address: andre@dem.feis.unesps-br

J. B. Aparecido: Department of Mechanical Engineering, São Paulo State University, (UNESP),

P. O. Box 31, CEP 15385-000, Ilha Solteira, SP, Brazil

E-mail address: jbaparecido@dem.feis.unesps-br 


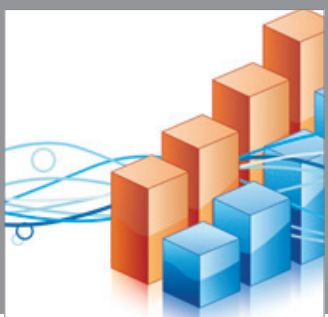

Advances in

Operations Research

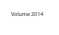

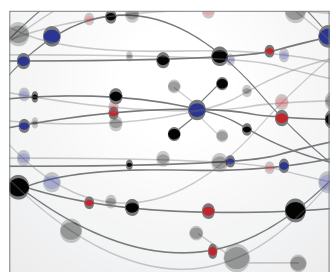

\section{The Scientific} World Journal
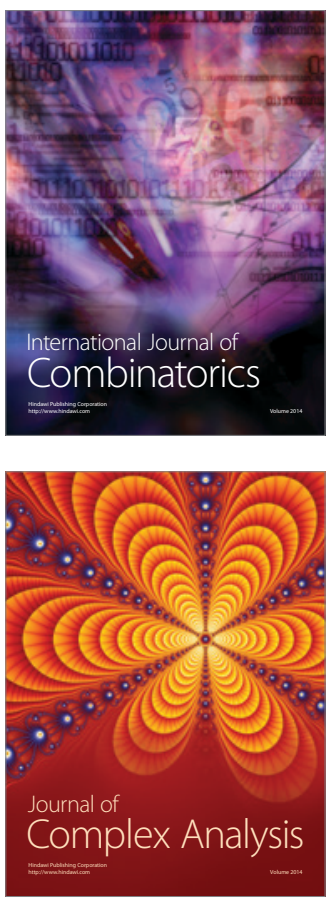

International Journal of

Mathematics and

Mathematical

Sciences
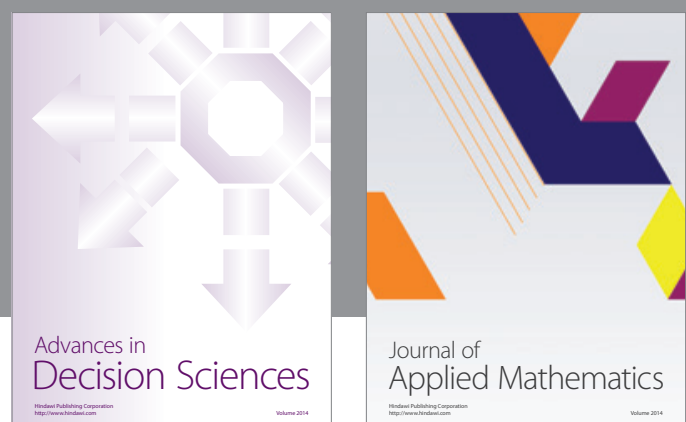

Journal of

Applied Mathematics
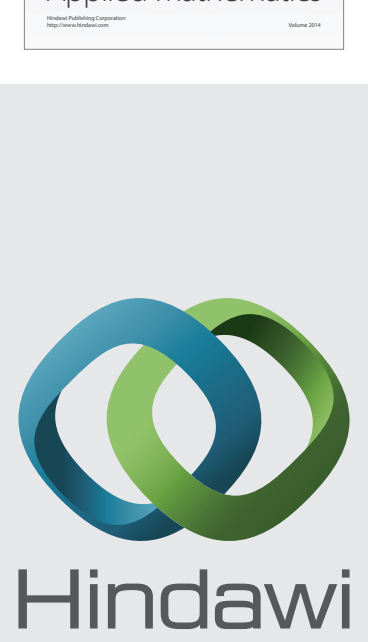

Submit your manuscripts at http://www.hindawi.com
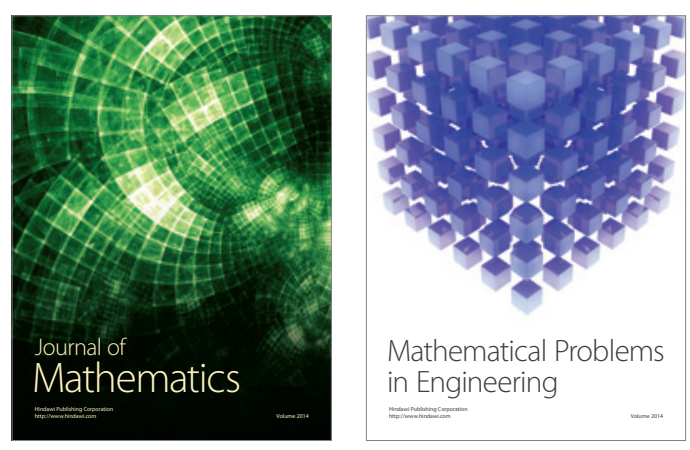

Mathematical Problems in Engineering
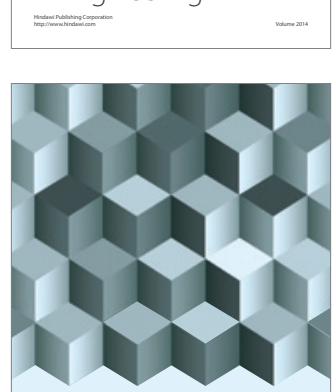

Journal of

Function Spaces
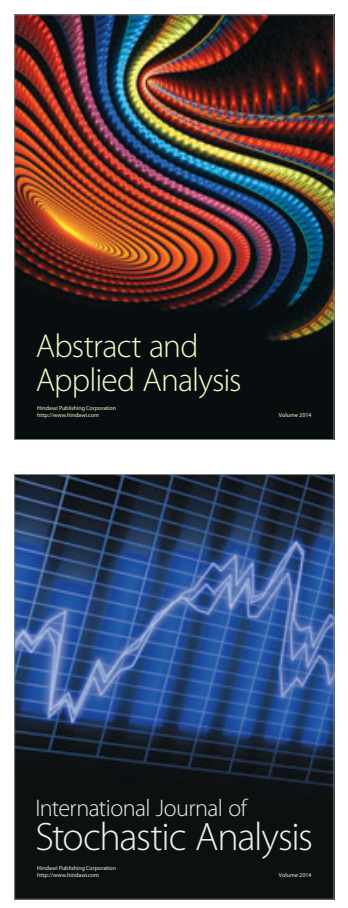

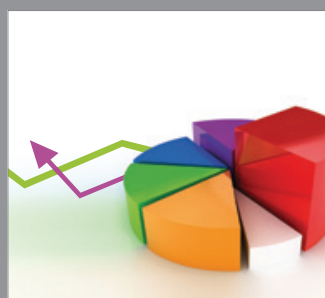

ournal of

Probability and Statistics

Promensencen
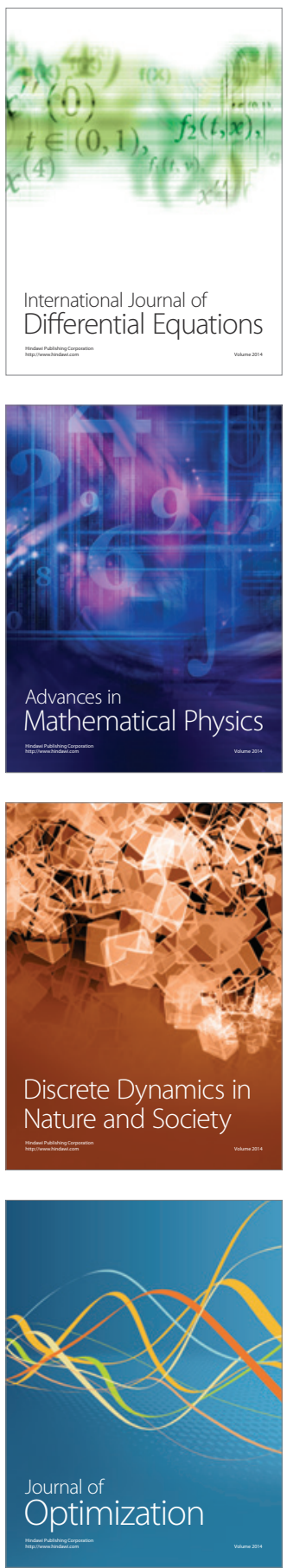